\title{
Introduction of a non-ported peripheral intravenous catheter with multi-use blood control septum offers improvements in the overall efficiency of the procedure and is clinically well accepted
}

\section{Dawn Michelle Cooper* and Malcolm David Whitfield}

\author{
Centre for Health Social Care, \\ Faculty of Health and Wellbeing, \\ Sheffield Hallam University, \\ Sheffield, S10 2BP, UK \\ Email: Dawn.Cooper@shu.ac.uk \\ Email: M.Whitfield@shu.ac.uk \\ *Corresponding author
}

\section{David Newton}

Central Procurement,

Nottingham University Hospitals NHS Trust,

Nottingham, NG5 1PB, UK

Email: David.Newton@nuh.nhs.uk

\section{Joseph Chiarella}

\author{
Accident and Emergency Department, \\ Queens Medical Centre, \\ Nottingham University Hospital NHS Trust, \\ Nottingham, NG7 2UH, UK \\ Email: Joseph.Chiarella@nuh.nhs.uk
}

\section{Katarzyna Karolina Machaczek}

Centre for Health Social Care,

Faculty of Health and Wellbeing,

Sheffield Hallam University,

Sheffield, S10 2BP, UK

Email: K.Machaczek@shu.ac.uk

\begin{abstract}
Financial challenges that the National Health Service (NHS), England, faces may jeopardise its future. This study evaluated the direct cost of using two different safety peripheral intravenous cannulae (SPIVC) with and without a blood control septum, including the cost of device and clinician time. Observation of 103 cannulations demonstrated a 54 second (29\%) time reduction per cannulation with the non-ported SPIVC with multi-use blood control septum (Introcan Safety® 3 B Braun), compared to the standard ported
\end{abstract}


SPIVC (Vasofix ${ }^{\circledR}$ Safety B Braun) $(\mathrm{P}<0.05)$. The direct cost analysis, including clinician time, demonstrated that the introduction of SPIVC with multi-use blood control septum could offer time efficiency savings equivalent to a reduction in average cannulation costs by $25 \% .82 \%$ of users perceived the insertion of SPIVC with multi-use blood control septum to be easy to use; $82 \%$ would choose to use it in clinical practice.

Keywords: cannula; time savings; time efficiency; non-ported cannula; non-ported catheter; PIVC; peripheral cannula; peripheral intravenous cannula; cost saving; innovation; blood control septum.

Reference to this paper should be made as follows: Cooper, D.M., Whitfield, M.D., Newton, D., Chiarella, J. and Machaczek, K.K. (2016) 'Introduction of a non-ported peripheral intravenous catheter with multi-use blood control septum offers improvements in the overall efficiency of the procedure and is clinically well accepted', Int. J. Healthcare Technology and Management, Vol. 15, No. 3, pp.177-193.

Biographical notes: Dawn Michelle Cooper obtained her BSc in Cellular and Molecular Pathology from the Bristol University in 2001 and PhD from the Human Nutrition Research Centre and Newcastle University in 2005 in the areas of Nutritional Bio-Mechanics and Bowel Cancer. Since then, she has moved into industry and currently works for B Braun Medical as the Research Analyst for the Anaesthesia and Intravenous Therapy Team and is a Visiting Research Fellow at the Centre for Health and Social Care Research at the Sheffield Hallam University.

Malcolm David Whitfield is a Professor of Health Economics and Management and the Director of the Health and Wellbeing Research Institute at Sheffield Hallam University. His doctorate was in the economic impact of cardio-vascular risk reduction in populations on future demand for acute services. The bulk of his research is around service and care pathway reengineering to improve the acceptability, clinical and cost effectiveness of services to patients.

David Newton has worked as a Registered Nurse for 22 years within the acute hospital sector and is currently a Matron in Clinical Procurement at the Nottingham University Hospitals NHS Trust. He is the Chair of the UK Clinical Procurement Specialist Network. As well as his Diploma in Nursing Studies, he has received his BA in Finance and studied his Masters in Public Health at Leeds, completing his studies in 2010. His professional interests involve evaluation of economic and real-world impacts of medical device changes within acute hospital environments and supporting high quality clinical outcomes through good procurement and clinical engagement.

Joseph Chiarella has worked for the NHS for 16 years, the last six of which have been in the Emergency Department (ED), Queens Medical Centre Nottingham. His role is split between Senior Clinical Support Worker and the Department of Research and Education in Emergency Medicine, Acute Medicine and Major Trauma (DREEAM) based within ED. He is the Education Lead for Venepuncture and Cannulation within the department, running the practical training, theory sessions and audits as well as core clinical skills. His past work includes ED project lead for safety cannulae and venepuncture devices and an ongoing research and study on the reduction of haemolysis within ED. 
Katarzyna Karolina Machaczek is a Public Health Specialist and Research Fellow in the Centre for Health and Social Care Research. She has been involved in a number of projects relating to public health which focused on prevention of cardio-vascular disease and mental health problems at the population level. Her current work includes health services evaluations and the development of sustained behaviour change interventions in relation to physical activity. In her work, she utilises qualitative and mixed-methods approaches.

\section{Introduction}

The National Health Service (NHS) spends over $£ 20$ billion each year on goods and services, which accounts for approximately $30 \%$ of the operating costs of each hospital trust. The UK Government plans to stabilise non-pay spending and it requires trusts to spend no more by the end of 2016 than they did in 2013 (NHS England, 2013). This means that trusts need to find over $£ 1.5$ billion of procurement efficiencies by the end of 2016. The Cabinet Office, Department of Health and NHS Business Services Authority have set a target of $£ 2$ bn savings for NHS procurement, with the NHS Supply Chain (http://www.supplychain.nhs.uk/news/company/150m-cash-releasing-savings-tobe-delivered-by-march-2016/) contract aiming to deliver $£ 150 \mathrm{~m}$ by March 31, 2016. Saving money on the procurement of supplies can be a straightforward process when the alternatives have the same specification and vary only in price. The challenge arises when product (a) works in a different way to product (b). In this case, the difference in the price on an individual component of a procedure may well not reflect the difference in value when considering a procedure as a whole. This gives rise to the potential for a false economy: "An apparent financial saving that in fact leads to greater expenditure" (Oxford Dictionary, 2014).

Procurement departments are under pressure to meet their saving targets whilst being encouraged to engage in innovation to change the fundamentals of the NHS (NHS Business Service Authority, 2014). This poses difficulties for procurement to meet their savings targets whist demonstrating they are embracing innovative change that will bring benefits to the organisation (Institute for Innovation and Improvement, 2014). Increasing the efficiency of frequently performed procedures can free up medical staff to deliver more patient-centred care (NHS England, 2014). The use of PIVC is an essential means to administer medicines, blood and blood products, for parenteral feeding and is one of the most common procedures to occur in healthcare (Maki et al., 2006). In the UK, one third of all patients admitted to the NHS will receive at least one PIVC (Boyd et al., 2011), giving an estimated 5 million patients per year (Castro-Sanchez et al., 2014). Reduction in time to undertake peripheral IV cannulation could release clinician time to deliver other healthcare procedures.

Of importance, intravenous catheter use is not without risk, from: phlebitis, cellulitis to sepsis amongst others (Curran and Reilly, 2008). Whilst the overall infection rate of PIVC is low $(0.1 \%)$, owing to the high frequency of use of PIVC the risk of infection is likely underestimated (Maki et al., 2006). In recent years, injection through stopcock injection ports has been identified as a potential portal of entry for microorganisms. In general closed catheter systems, used with the appropriate disinfection, have been 
associated with fewer catheter-related blood stream infections (Casey et al., 2007; O'Grady et al., 2011; Niel-Weise et al., 2006; Soothill et al., 2009). However, Esteve et al. (2007) claim that closed catheter systems do not reduce infection rates. Owing to the similar setup of cannula top ports and injection ports of stopcocks, there has been an increase in the use of non-ported cannula within the UK over the last few years, with an estimated $22 \%$ of the NHS now using a non-ported cannula with a vascular access device (VAD) (unpublished market research data). There is increasing interest from infection control departments in hospitals, to implement non-ported cannulae with a VAD. However, there is a scarcity of studies exploring the use of the top injection ports.

\section{The study}

\section{$2.1 \operatorname{Aim}$}

The aim of this study was two-fold:

1 to provide a time efficiency analysis comparing the use of a novel non-ported safety peripheral intravenous cannulae (SPIVC) with multi-use blood control septum against current practice and to correlate this saving with possible cost offset

2 to explore the clinical acceptance of a novel non-ported SPIVC with multi-use blood control septum amongst NHS staff in the UK.

\subsubsection{Methods: time in motion study}

The time and motion study was a prospective, non-blinded, cohort, controlled single-centre, post market study, conducted in the Emergency Department of Nottingham Queens Medical Centre in Nottingham, the UK. The main body of the study was designed to compare the effects of using a complete cannulation pack inclusive of cannula, compared with the current practice of collecting all separate components for the procedure separately. Timings in this study were collected:

1 after collection of all items

2 at arrival back at patient bed side

3 after preparation of equipment and just prior to skin cleansing

4 from skin cleansing and after connection of VAD and documentation completed.

The time in motion data here consists of an analysis of stage (4) only, comparing the use of a non-ported SPIVC with multi-use blood control septum (Introcan Safety ${ }^{\circledR} 3$ B Braun Medical), compared with a ported SPIVC (Vasofix ${ }^{\circledR}$ Safety B Braun Medical). In both arms of the study, a VAD was applied to the cannula (Smartsite ${ }^{\circledR}$, Alaris). The study was part of an in-service product evaluation within the NHS Trust. For the first arm of the study participants used the current ported SPIVC and separate components and used for the second arm, the cannulation packs with non-ported SPIVC with multi-use blood control septum were used. All cannulating staff were invited to participate in the study. 


\subsubsection{Participants: time in motion}

All cannulating staff including junior doctors and nurses (Bands 5 and 6) in Nottingham Queens Medical Centre Emergency Department were eligible for participation and received training on the non-ported SPIVC with multi-use blood control septum for a week prior to the commencement of the study. No data on the patients was collected, only clinician time was measured. Permission from the Research and Development Centre of Nottingham University Hospitals NHS Trust was granted for this study.

\subsubsection{Data collection: time in motion}

Three researchers collected the data overall. Prior to the study the researchers observed $\times 10$ simulated cannulations each and there were no differences in their recordings of the timings. Days for observation and which cannulations on those days to observe were randomised by coin toss. One researcher observed and collected data on cannulations on a specific day. This meant that the researcher could observe one procedure at a time; missing any other procedures taking place at the same time. The time taken was recorded with a stopwatch.

\subsubsection{Statistical analysis: time in motion}

Sample size calculation for full time in motion study, comparing separate components with packs was based on estimation by clinical user of 300s per cannulation, a SD of $120 \mathrm{~s}$, a difference between means of $90 \mathrm{~s}$, power of $80 \%$ and alpha of 0.05 . The estimated $300 \mathrm{~s}$ per cannulation was confirmed with the observation of five cannulations prior to the study. This resulted in a sample size of 28 cannulations in each arm of the study. As this was based on timings from a small sample we aimed for a minimum of 50 samples per each study arm to be sure of effect. Statistical analysis was performed using a standard Student's t-test for continuous variables.

\subsection{Methods: clinical users' perception}

Clinical users' perceptions phase of the study was preceded by a familiarisation stage where data was collected by the research team and used to produce the sample size for the full study. Clinical users' perceptions of Introcan Safety ${ }^{\circledR} 3$ were conducted in 14 NHS Trusts in the UK. The clinical users received training on Introcan Safety ${ }^{\circledR} 3$ before the study commenced.

The data from all of the evaluation forms $(n=212)$ were explored: Previous type of cannula used (ported/non-ported), hospital trust, department, type of clinician, number of Introcan Safety ${ }^{\circledR} 3$ inserted, was Introcan Safety ${ }^{\circledR} 3$ easy to insert? Was Introcan Safety ${ }^{\circledR} 3$ easy to penetrate the patient's skin? Was first and second flashback easy to see? Is the cannula secure when dressed? Does the multi-use blood control septum prevent backflow of blood without digital vessel occlusion? Would you use Introcan Safety ${ }^{\circledR} 3$ in clinical practice?

The effects of previous cannula used, department and clinician type were investigated for effect on responses. 


\subsubsection{Participants: clinical users' perception}

Departments with high cannula use were identified for participation; computerised tomography (CT) and magnetic resonance imaging (MRI) departments, oncology, surgical wards, emergency departments (EDs) and medical assessment suite (MAS). All staff members working in those departments were invited to participate in the study. No incentives were offered to the participants. The data was collected between May 2012 and September 2014.

\subsubsection{Sample size calculation: clinical users' perception}

Sample size for the evaluation prior to clinical users' perceptions phase of the study was based on our wanting to demonstrate that greater than $80 \%( \pm 5 \%)$ of clinicians would respond favourably to the non-ported SPIVC with multi-use blood control septum. This was based on a pre-familiarisation phase prior to the main study, which demonstrated an approximate $80 \%$ positive score. A sample size of 153 was required, in order to allow for a $50 \%$ failure to complete forms, evaluations forms were sent to 306 participants in the second week of evaluation. In some instances, the user did not answer all questions and resulted in a variable $\mathrm{n}$ value; for each question the percent value is based solely on the participants who answered the questions.

\subsubsection{Statistical analysis: clinical users' perception}

Comparisons were made between different external factors and effect on the clinical user's responses. External factors included previous cannula use (ported versus non-ported), healthcare departments and type of clinical practitioners. Comparisons were performed using chi-squared test with post hoc comparison of residual values (Sharpe, 2015).

\subsection{Cost impact}

The key cost vectors identified to be directly impacted by the study were:

1 the cost of the cannula

2 the cost of the clinician time to complete the procedure.

Other costs that were viewed as constants (e.g., building costs) or not directly impacted by the introduction of a SPIVC with multi-use blood control septum were not included into cost analysis.

The cost of the current cannula was calculated based on the average unit price of the two current main SPIVC used in the NHS based on the NHS Supply Chain Catalogues (http://www.supplychain.nhs.uk/) price (the main supplier of medical equipment to NHS Trusts in the UK) in 2015 including VAT and delivery. Costs did not account for any increase over time and are calculated at the current level. Cost of clinician time to NHS Trust were calculated as per Figure 1 - these calculations produced an average hourly cost to a NHS Trust of $£ 22.77$ per hour, for clinicians who cannulate and for the purposes of calculations assume equal split amongst the different cannulators on different pay bandings and is a representation of average cost to NHS Trust for clinician time. 
Figure 1 Flow chart for calculations of cost of clinician time as a cost to NHS Trust

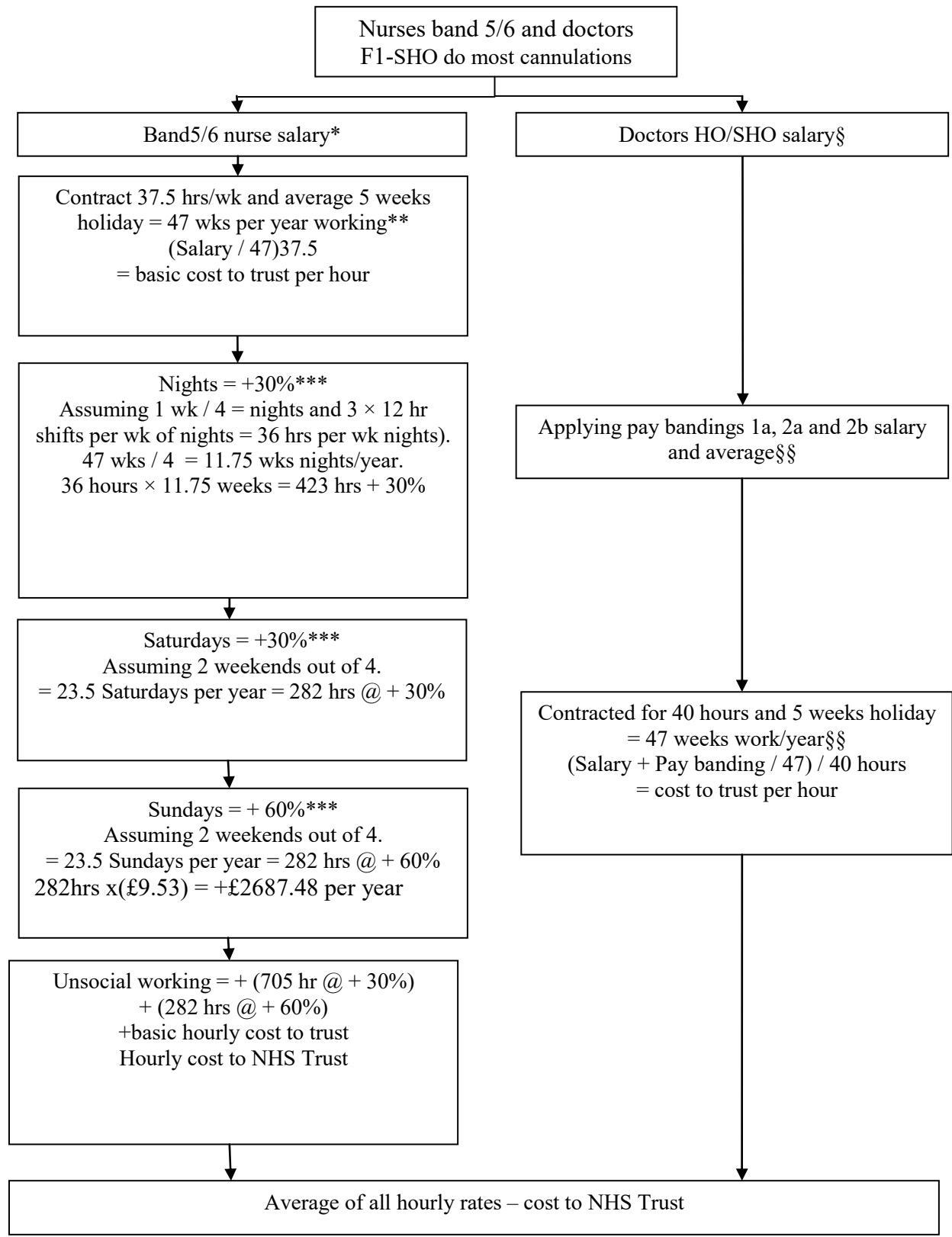

Notes: *Salary for Nurses (NHS Careers, 2013).

**Based on 37.5 hour week and average holidays of 37 days per year (Payscale, http://www.payscale.com/research/UK/Job=Staff_Nurse/Salary).

***Unsociable working appropriate for pay band 5 and 6 (NHS Careers, 2013).

§Junior Doctors salary (NHS Employers, 2014).

$\S \S$ Additional pay bandings (Department of Health Social Services and Public

Safety, 2000; British Medical Association, http://bma.org.uk/practical-support-atwork/ewtd/ewtd-juniors). 
For the overall cost offset, estimates of organisational level impact assumed that non-ported safety SPIVC with multi-use blood control septum could be introduced for $60 \%$ of NHS Trust cannula use, based on usage data in other NHS Trusts (unpublished B Braun sales data 2014), with the remaining $40 \%$ to be a ported SPIVC being used in areas such as theatres for rapid induction, resuscitation for immediate access via top port and also delivery departments. Cost effectiveness, calculated cost invested in SPIVC with multi-use blood control septum per hour clinician time saved.

\section{Results}

\subsection{Main findings: time in motion study}

Twenty-nine clinicians took part in the study. In arm one there were 14 clinicians and 15 in arm two. There was an overlap of five clinicians whose cannulations were observed in both arms of the study. The time taken from skin cleansing through to completion of cannulation and documentation was an average of 185 s (95\% CI 154 s-216 s) when clinicians were using the ported SPIVC (Table 1) and was reduced to an average of $131 \mathrm{~s}$ (95\% CI 114 s-148 s) when using the non-ported SPIVC with multi-use blood control septum. The time to complete the final stage alone was reduced by an average of $54 \mathrm{~s}$ $(29 \%)(\mathrm{P} \leq 0.005)$ by the introduction of the non-ported SPIVC with multi-use blood control septum.

Table 1 The table illustrates time (in seconds) taken from skin cleansing to completion of cannulation, with attachment of the VAD and completion of paperwork for the two different cannula systems, the same VAD and documentation was used in both arms of study

\begin{tabular}{lccccccc}
\hline & \multicolumn{7}{c}{ Time (seconds) } \\
\hline & $n$ & Mean & SD & $95 \%$ CI & Min & Median & Max \\
\hline Overall & 103 & 158 & 95 & $140-176$ & 14 & 136 & 642 \\
Vasofix ${ }^{\circledR}$ Safety & 51 & 185 & 114 & $154-216$ & 30 & 167 & 642 \\
Introcan Safety ${ }^{\circledR} 3$ & 52 & 131 & 62 & $114-148$ & 14 & 130 & 300 \\
P value & \multicolumn{7}{c}{$\mathrm{P}<0.005$} \\
\hline
\end{tabular}

\subsection{Estimated impact upon utilisation of staff time and cost offset}

Introduction of the SPIVC with multi-use blood control septum (for $60 \%$ of cannula) into a large NHS Trust of 1,650 beds (such as the site used for this study) using 300,000 cannula, would result in releasing up to 2,700 hours on nursing/junior doctor time p.a. This assumes an approximate use of 185 cannula per bed; based on trust cannula volumes (unpublished B Braun sales data 2012/13) and bed number from 36 UK NHS Trusts websites (95\% CI 177-194). Factoring in an hourly rate of $£ 22.77$ per hour (range $£ 15.61-£ 34.31$ ) a large 1,650 bed NHS Trust could release $£ 61,479$ of staff resource in efficiency improvement (range $£ 42,147-£ 92,637$ ). The above calculation looks only at the time efficiency saving but does not factor in the extra investment required for the introduction of a SPIVC with multi-use blood control septum. Introduction of a SPIVC with multi-use blood control septum, for $60 \%$ of the cannula in a trust of 1,650 beds, would result in an average investment of $£ 9,900$ per annum (range $£ 0.00-£ 19,800$ ) 
compared to the average cost of the two most commonly used SPIVC in NHS supply chain catalogue inc VAT. Factoring in the investment in a SPIVC with multi-use blood control septum, the average efficiency improvement could be of a 1,650 bed trust could be $£ 53,530$ per annum (25\% of current IVC spend) (range $£ 22,374-£ 92,637$ ). These cost offset calculations look only at the direct costs associated with cannulation. Other indirect and institution costs were not included into this calculation for simplicity and transparency. Cost effectiveness calculations demonstrated an average investment of $£ 3.67$ per hour of clinician time saved (range $£ 0.00-£ 7.33$ per hour saved depending of current SPIVC used). This is $84 \%$ less than the cost to NHS Trust for one hour of clinician time.

\subsection{Main findings of the clinical users' perception study}

In total, 212 forms were completed and Figure 2 demonstrates the overall results from the clinical user perception study. Overall, $70 \%$ of clinicians agreed or strongly agreed that the SPIVC with multi-use blood control septum was easy to use with minimum change in technique ( $\mathrm{n}=147$ out of 211$)$. 84\% of clinicians agreed or strongly agreed that the SPIVC with multi-use blood control septum penetrated the skin/vessel easily $(n=179$ out of 212). Of the $8 \%$ of respondents who found it difficult to penetrate skin/vein ( $n=17$ out of 212), 15 of these users had used the cannula infrequently (nine times or less) indicating a trend for increased ease of use with increased familiarity. $80 \%$ of users agreed or strongly agreed that both flashbacks were seen easily $(n=169$ out of 212$)$. The first flashback is the first back flow of blood into the flashback chamber of a cannula. The second flashback is seen in the catheter tip as the stylet is withdrawn and catheter advanced. Flashbacks are used to determine successful puncture and advancement of catheter into the vein. Similarly, $80 \%$ of users agreed or strongly agreed that cannula was secure when dressed $(n=168$ out of 211$) .87 \%$ of clinicians $(n=184$ out of 210$)$ agreed or strongly agreed that the multi-use blood control septum prevented the back flow of blood, with only $5 \%$ users commenting that back flow of blood was still present $(n=11$ out of 210). Of these, two users removed the stylet very slowly ( $>15 \mathrm{~s})$ keeping the septum open and on one occasion the clinician removed the hydrophobic stopper from flashback chamber so saw 'leaking' outside of the remit of the septum.

Figure 2 Overall results from Introcan Safety ${ }^{\circledR} 3$ UK wide evaluation, results from $n=212$ clinicians

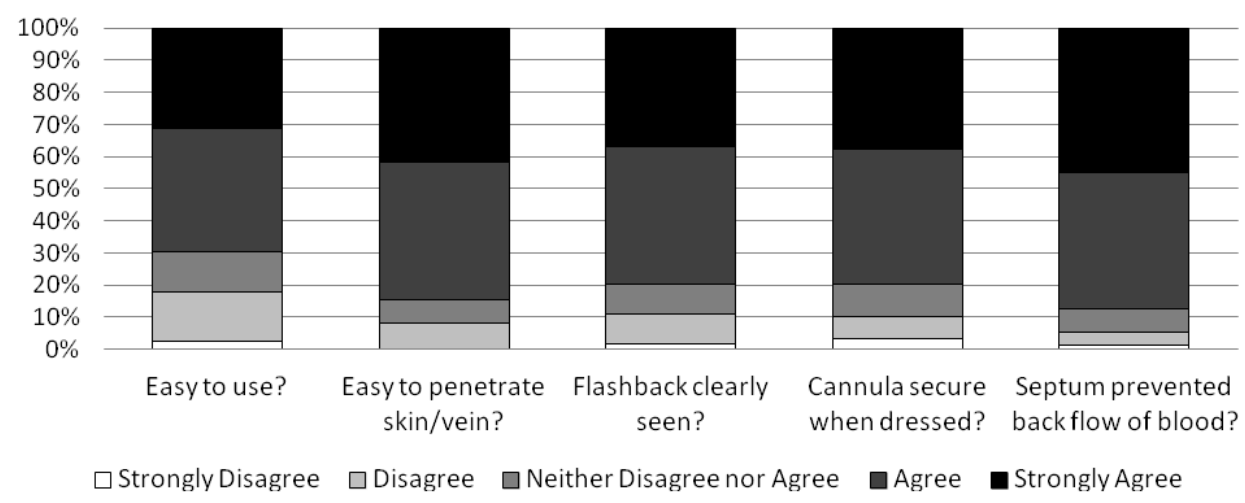


Figure 3 Clinical user perception responses - represented by clinical department (see online version for colours)

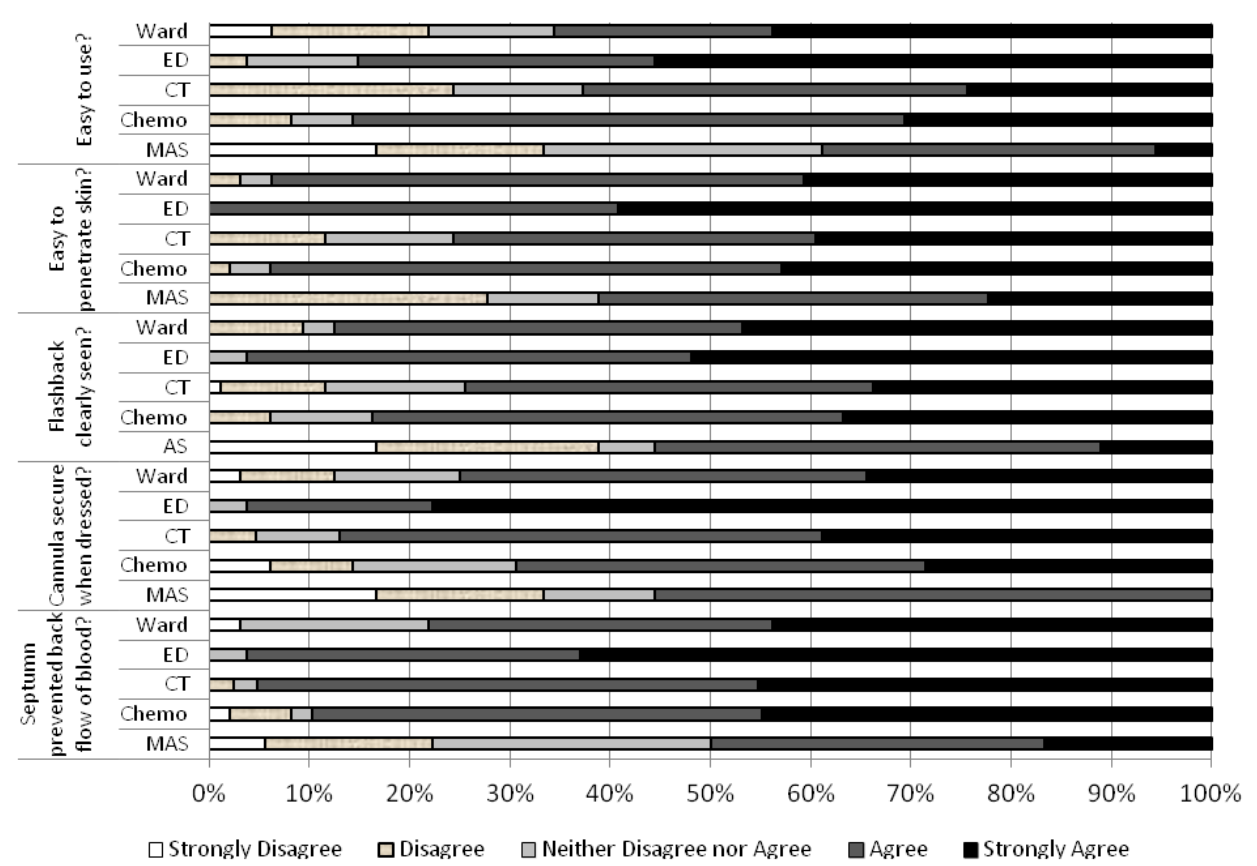

Notes: $\mathrm{ED}=$ emergency department, $\mathrm{CT}=$ computerised tomography and magnetic resonance imaging, Chemo $=$ chemotherapy, $\mathrm{MAS}=$ medical assessment suite.

Evaluation forms were collected from five types of clinical areas: computerised tomography and magnetic resonance imaging departments (CT) (40.6\%), oncology $(23.1 \%)$, surgical wards (15.1\%), ED (12.7\%) and MAS (A step down unit from EDs in the UK) $(8.5 \%)$. The responses from the MAS were different to all other areas for 5 of the 6 questions asked (Figure 3). More clinical users from the MAS strongly disagreed that SPIVC with multi-use blood control septum was easy to use with minimum change in technique $(16.7 \% \mathrm{n}=3$ out of 18$)(\mathrm{P}<0.05)$ compared to other clinical departments $(0 \%-6.25 \%)$. More clinical users from the MAS strongly disagreed that the first and second flashbacks were easy to see $(16.7 \% \mathrm{n}=3$ out of 18$)(\mathrm{P}<0.05)$ compared to other clinical departments $(0 \%-3.13 \%)$. In addition, more clinical users from MAS disagreed that the SPIVC with multi-use blood control septum penetrated the skin/vessel easily $(27.8 \% \mathrm{n}=5$ out of 18$)(\mathrm{P}<0.05)$ compared to other clinical departments $(2 \%-11 \%)$. When asked if the cannula was secured when dressed, more clinicians from MAS strongly disagreed $(16.7 \% \mathrm{n}=3$ out of 18$)(\mathrm{P}<0.05)$ compared with other clinical areas $(0 \%-6.1 \%)$. When asked if the blood control septum prevented the back flow of blood, more clinicians from MAS disagreed $(16.7 \% \mathrm{n}=3$ out of 18$)$ and neither agreed nor disagreed $(27.8 \% \mathrm{n}=5$ out 18$)(\mathrm{P}<0.05)$ compared with other areas $(0 \%-6.1 \%$ and $2 \%-3.7 \%$, respectively). The results from MAS accounted for only $8.5 \%$ of the evaluations completed $(\mathrm{n}=18)$, this small number may have skewed the data when comparing effect of department. However, overall in response to 'would you use Introcan Safety ${ }^{\circledR} 3$ in clinical practice', the majority of clinicians in the MAS responded with 'yes' $(72.2 \% \mathrm{n}=13$ out of 18$)$ and was in line with other departments $(77.2 \%-92.9 \%)$. 
Another difference between the departments was noted in the EDs, here more clinicians strongly agreed that 'that Introcan Safety ${ }^{\circledR} 3$ was easy to use' $(55.6 \% \mathrm{n}=15$ out of 27$)$ $(\mathrm{P}<0.05)$ (Figure 4).

Various clinicians completed evaluation forms: radiographers $(39.6 \%)$, nurses (34.9\%), doctors $(21.7 \%)$, and healthcare assistants (HCA's) (3.8\%) (who cannulate in some trusts). More of the HCA's strongly agreed that the SPIVC with multi-use blood control septum penetrated the skin/vessel easily $(87.5 \% \mathrm{n}=7$ out of 8$)(\mathrm{P}<0.05)$ compared with other clinicians $(38.1 \%-41.3 \%)$. More HCA's strongly agreed that the SPIVC with multi-use blood control septum was secure when dressed $(100 \% \mathrm{n}=8$ out of 8) $(\mathrm{P}<0.05)$ compared with other clinicians $(28.3 \%-37.3 \%)$. There were only eight responses by HCA's $(3.8 \%)$, which may have skewed the data from this subset when comparing to other clinicians. More medics strongly disagreed that the first and second flashbacks were easy to see in the SPIVC with multi-use blood control septum $(6.5 \%$ $\mathrm{n}=3$ out of 46$)(\mathrm{p}<0.05)$ compared to other clinicians $(0 \%-1.2 \%)$. However, overall there was no difference between the clinicians when asked, 'Would you use this device in clinical practice' with all groups falling in the range $77.5 \%-88.9 \%$.

Figure 4 Percent responses to 'would you use Introcan Safety ${ }^{\circledR} 3$ in clinical practice?'

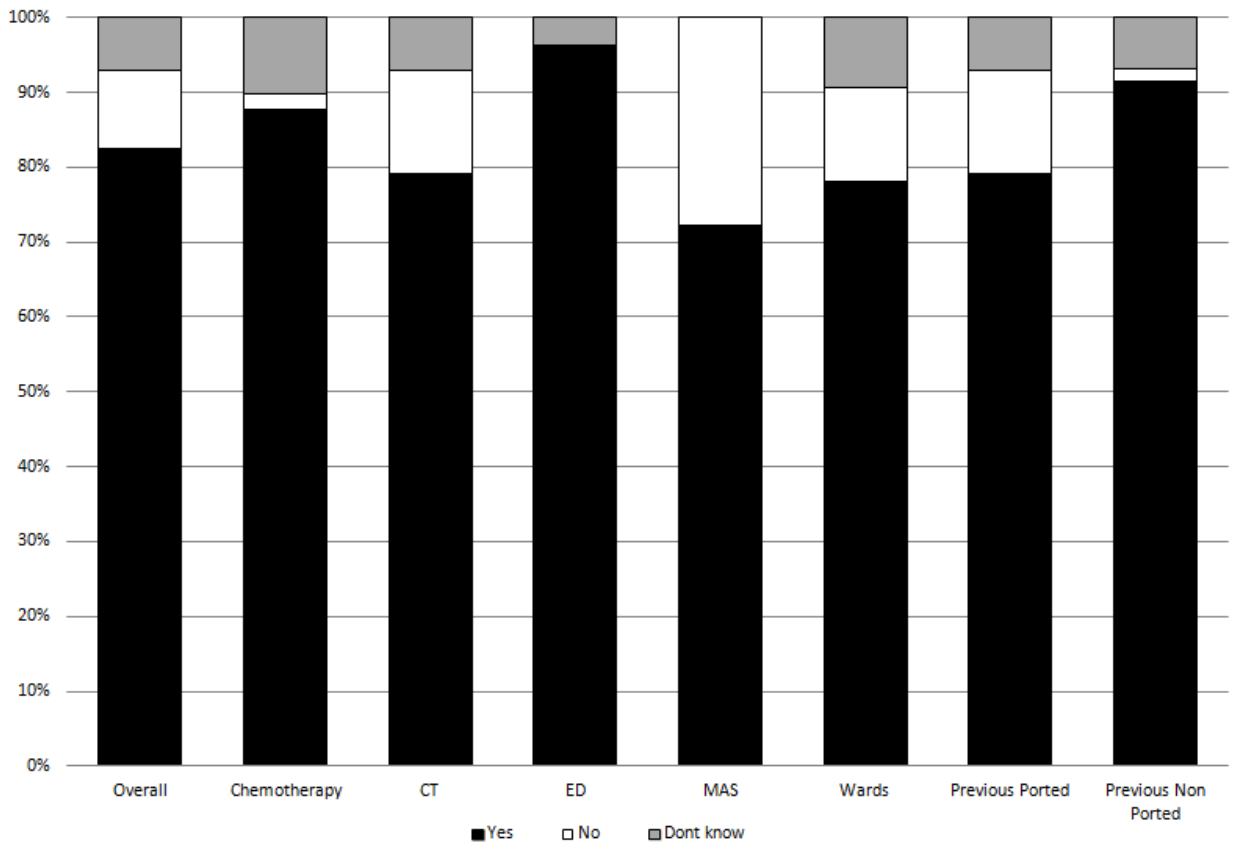

Notes: Answers expressed as overall, department and by previous cannula use.

$\mathrm{CT}=$ computerised tomography and magnetic resonance imaging,

$\mathrm{ED}=$ emergency department, MAS $=$ medical assessment suite.

Overall $82 \%$ ( $n=174$ out of 212 ) of clinicians would use the SPIVC with multi-use blood control septum in clinical practice (Figure 4$) .10 \%$ of clinical users $(n=22$ out of 212) would not choose to use SPIVC with multi-use blood control septum in clinical practice. Of the 22 users who would not use the non-ported SPIVC with multi-use blood control septum, 21 had previously exclusively used a ported cannula, indicating more 
concern when moving from a ported to non-ported SPIVC. Twelve users commented on difficulty in changing technique with a non-ported cannula, seven clinicians did not comment as to why they would not use, three found it more difficult to dress the cannula and seven did not see the flashback clearly.

Figure 5 Clinical user perception responses - represented by clinician type (see online version for colours)

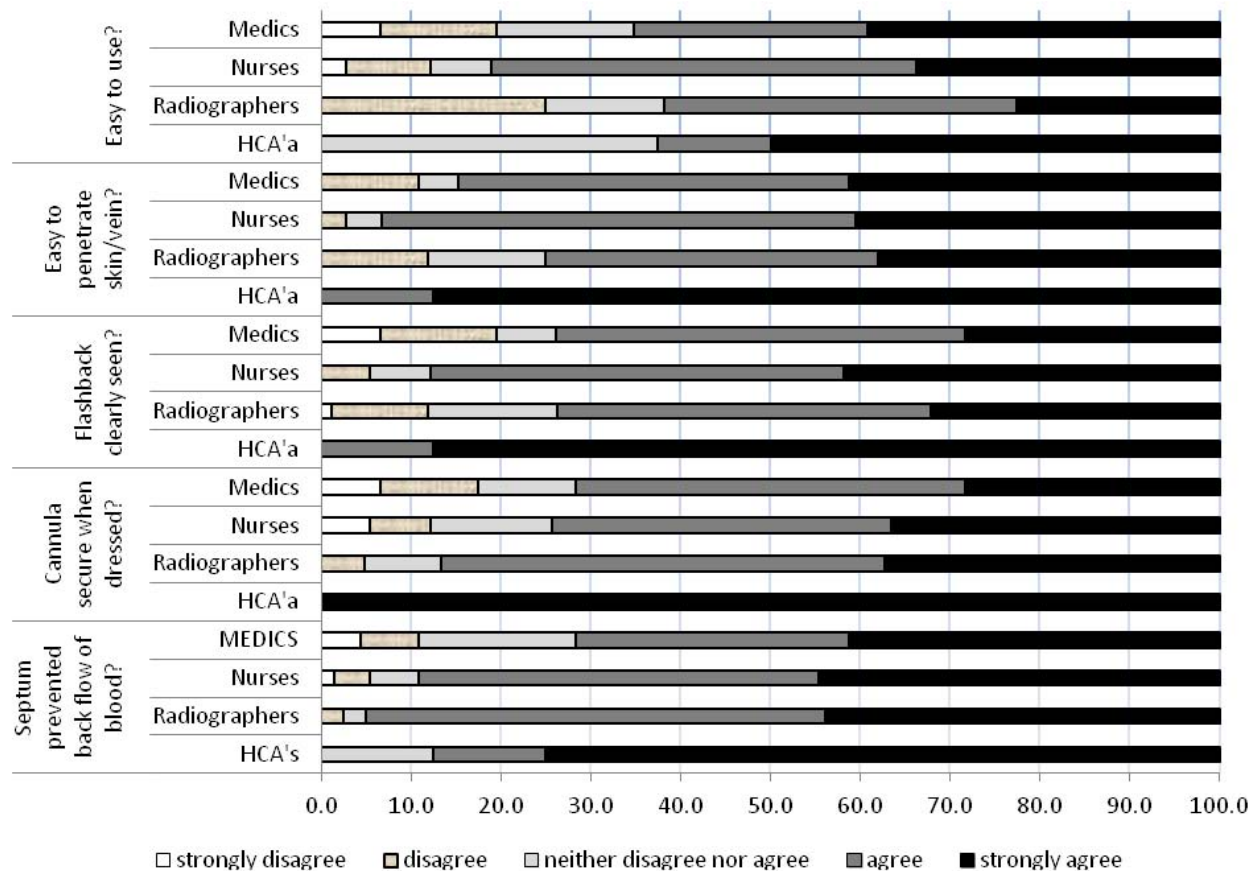

$69 \%$ of users agreed or strongly agreed that there was a minimal change in technique $(n=147$ out of 212). Clinicians familiar with a ported cannula found that there was a larger change in technique $(22.7 \%, \mathrm{n}=35$ out of 154$)$ compared to users familiar with non-ported cannula $(6.9 \%, \mathrm{n}=4$ out of 58$)$. Indeed, significantly more clinicians who were previously using a non-ported cannula, strongly agreed that the SPIVC with multi-use blood control septum was easy to use with minimal change in technique $(46.5 \%, \mathrm{n}=27$ out of 58$)$ compared to previous ported cannula users $(25.3 \% \mathrm{n}=39$ out of 154) ( $\mathrm{P}<0.05)$. In addition, fewer clinicians, previously using a non-ported cannula, responded that they would not choose to use the SPIVC with multi-use blood control septum $(\mathrm{P}<0.05)(1.7 \%, \mathrm{n}=1$ out of 58$)$ compared to previous ported cannula users $(14.3 \% \mathrm{n}=22$ out of 154$)$.

\section{Discussion}

Since its launch in 1948, the NHS has grown to become the world's largest publicly funded health service. The NHS deals with over 1 million patients every 36 hours and in a recent survey found that there was $60 \%$ more operations completed by the NHS in 
$2012 / 2013$ compared to $2002 / 2003$, with an increase from 6.6 million to 10.6 million. The total annual attendance at EDs was $32 \%$ higher than a decade earlier (NHS Confederation, http://www.nhsconfed.org/resources/key-statistics-on-the-nhs). The NHS is likely to face further pressures as the UK population is estimated to increase from an estimated 63.7 million 2012 to 71.04 million by 2030. Furthermore, the number of people aged 65 and over is projected to increase from $10.84 \mathrm{~m}$ in 2012 to $17.79 \mathrm{~m}$ by 2037 . As part of this growth, the number of over- $85 \mathrm{~s}$ is estimated to more than double from 1.44 million in 2012 to 3.64 million by 2037 (NHS Confederation, http://www.nhsconfed.org/resources/key-statistics-on-the-nhs). With the increasing numbers of patients requiring the NHS services it is imperative that clinicians are able to work in the most efficient means possible. With one third of all patients in the UK admitted to the NHS receiving at least one PIVC (Boyd et al., 2011) this is an area of time consumption to the NHS staff.

This study has demonstrated in one A\&E department an average time saving of $54 \mathrm{~s}$ (29\%) per cannulation when using a novel non-ported SPIVC with multi-use blood control septum when compared to a ported SPIVC. The presence of a blood control septum removes the requirement for a clinician to occlude the vein, hence freeing up a second hand to secure the SPIVC while the stylet is removed, VAD is attached and dressing applied, which may well account for the time saving observed. Previously, in Haeseler et al. (2014), using the same non-ported SPIVC with multi-use blood control septum, in a study of 200 cannulations in a pre-operative setting, reported a time saving of $10 \mathrm{~s}$ from venepuncture to attachment of VAD and a time saving of $15 \mathrm{~s}$ from venepuncture to fully dressed cannula. Furthermore, Haeseler et al. (2014) observed that vein occlusion was required in $2 \%$ of cannulations with the non-ported SPIVC with multi-use blood control septum compared with $96 \%$ of cannulations with a standard SPIVC without blood control septum. Also, $80 \%$ of the clinicians that did not compress the vein stated that omission of vein compression improved the procedure of cannulation since both hands could be used during removal of the needle and catheter connection. It is interesting that in the controlled environment of the pre-operative setting that a time saving was also found, albeit less than observed here, and this may be due to the differences in patients and conditions in the differing areas. It is difficult to directly compare these two studies as different stage markers were used for timings and the two study areas are very different. It is likely that the greater time saving observed here in the A\&E department may be due to greater variation in patient compliance and ease of venous access. Indeed, it was commented by the users on seven occasions that the venous access was difficult. Of these seven 'difficult to cannulate' patients, five occurred during the use of the standard ported safety SPIVC section of the trial and two occurred while the non-ported safety SPIVC with multi-use blood control septum was being timed. Even though the users commented on these patients being difficult, all except one was inside the normal variation of cannulation times across the two groups.

There is a risk of potential infection to healthcare workers with each application of any PIVC as the clinician is exposed to patient's blood. The risk of accidental needlestick injury could be near eliminated by the introduction of a safety cannula (Asai et al., 1999; Prunet et al., 2008) and in light of this view the EU Council Sharps Directive 2010/31/EU came in to action in April 2013 recommending the use of sharp safe products in the healthcare setting. Haeseler et al. (2014) observed that the septum prevented backflow of blood in $95.1 \%$ of cannulations from the non-ported SPIVC with blood control septum, 
whereas use of a SPIVC without septum, using standard occlusion techniques, only prevented back flow in $32.5 \%$ of cannulations. They also observed that upon manipulation of the SPIVC (for catheter connection and disconnection procedures such as blood sampling or change of infusion line) there was no blood leakage with the non-ported SPIVC with multi-use blood control septum compared to $74 \%$ of manipulations with the non-ported SPIVC without septum. In addition, Seiberlich et al. (2015) (using a different SPIVC with septum to prevent back flow of blood for initial venepuncture) found than digital compression was not required to prevent back flow of blood when a non-ported SPIVC with a blood control septum was used (95.5\%), compared to using a non-ported SPIVC without septum (19.1\%). Prevention of exposure to blood may protect healthcare workers from exposure to potential blood borne pathogens and supports best practise for healthcare workers (Health and Safety at work Act, 1974; Jagger et al., 2011; Shillie et al., 2013). While this study was not directly designed to measure success rate of the multi-use septum, only $5 \%(n=11$ out of 214$)$ of users in the clinical evaluation commented that there was still back flow of blood. Anecdotally, clinicians during the evaluation did comment positively on there being 'less mess with these new cannulas', further demonstrating that there is a perceived benefit of the multi-use blood control septum to the clinician. The clinical evaluation here was not designed as a full in-depth qualitative study. In light of the anecdotal comments received it would be of interest to obtain a full qualitative report of the healthcare workers perception of the multi-use blood control septum and how this impacts their practice.

Here we further looked at the cost offset of introducing Introcan Safety (R) 3 into NHS Trusts in the UK by factoring in additional cost of the SPIVC with multi-use blood control septum compared to the time saved as a cost of clinician time to the trust. Healthcare workers time accounts for $40 \%$ of the NHS annual expenditure (General Election, 2010). Ensuring healthcare workers time is utilised to the best it can be has been the focus of government initiatives such as The Productive Series. This initiative set out by the Institute of Innovation and Improvement supports NHS teams to redesign and streamline the way they manage and work. The aim is to achieve significant and lasting improvements, predominately in the extra time that they give to patients, as well as improving the quality of care delivered whilst reducing costs. The study results reported in this paper are from a one site study in one department and need to be interpreted with caution.

There is also a nature of human error possible in the recording of the timings on the data as three different observers were used. Prior to the study, the three observers simultaneously observed ten practice scenarios setup in a lab using a training arm and different cannulators - under these circumstances there was SD of 0.45 seconds between the timings measured by the three observers demonstrating minimal error, however a lab setup is different from the real scenario in a busy ED and a level of error could be expected.

It was impossible to blind the timing observers. Clinicians were aware they were being timed and that may have impacted on the timings of the study. Indeed, the observers commented that some staff did become very enthusiastic to 'beat the clock' initially when using the current cannulation equipment. However, it was also noted that this enthusiasm waned as the study went on; despite this a time saving was demonstrated by using the SPIVC with multi-use septum. 
A larger study across multiple sites and multiple departments would provide further evidence on the potential impact of clinician time saving that might be made.

With this introduction of the European Union safety directive on sharps (European Commission Directive, 2010), the Health and Safety Executive issued a guide for the NHS employers and employees to assist in the compliance. This guide recommending that end users were engaged in the selection process of any sharp safe devices to be introduced into an NHS Trust (HSE, 2013). This study also investigated the clinical user perception of a new SPIVC with multi-use blood control septum and found that the majority of end users, from a range of institutions and clinical backgrounds, found the device would be chosen for clinical use by the majority of clinical users. Clinical acceptability studies are rare, however, other blood control SPIVC's have also been demonstrated to be clinically accepted in single centre studies in the USA (Seiberlich et al., 2015; Onia et al., 2011), and these studies also demonstrated the reduced need for digital compression to prevent back flow of blood. These two studies, based in the USA, compare a like for like cannula with the new version containing a blood control septum. In the USA, it is standard practice for a non-ported cannula to be used, which is not as common a practice in the UK. In this current study, the evaluators were a mix of current ported cannula users (75\%) and non-ported cannula users (25\%). Noticeably only $1.7 \%$ of the current non-ported cannula users would not use the SPIVC with blood control septum, in agreement with the observations in the USA. However, for the majority of users, who had to change cannulating technique to use a non-ported cannula, there was an increase to $14.3 \%$ of clinicians choosing not to use. The clinical user perception study took place for two weeks, having $86 \%$ of users choosing to use or neutral to using the new SPIVC even with a change in technique is of interest in the UK where infection control teams are looking to introduce closed systems due to high contamination rates of top ports (Oberhammer 1979).

\section{Summary and conclusions}

The study indicates that introduction of a non-ported SPIVC with multi-use blood control septum could be well received, with the appropriate level of training of healthcare staff. The study has revealed a time saving of $\sim 29 \%$ per cannulation (54s), compared to standard cannulation practices. This may suggest that introduction of non-ported SPIVC with multi-use blood control septum may provide efficiency savings across a trust; however this will vary depending on current practices within each hospital and also with differing practices within different areas of the trust.

\section{Conflicts of interest}

D. Cooper is an employee for B Braun Medical as the Research Analyst for the Anaesthesia and Intravenous Therapy Team. Introcan Safety ${ }^{\circledR} 3$ cannula were provided by B Braun Medical for the purposes of the study. No other conflicts to be declared. 


\section{References}

Asai, T., Matsumoto, S., Matsumoto, H., Yamamoto, K. and Shingu, K. (1999) 'Prevention of needle-stick injury', Anaesthesia, Vol. 54, No. 3, pp.258-261.

Boyd, S., Aggarwal, I., Davey, P., Logan, M. and Nathwani, D. (2011) 'Peripheral intravenous catheters: the road to quality improvement and safer patient care', Journal of Hospital Infection, Vol. 77, No. 9, pp.37-41.

British Medical Association, 'European working time directive for junior doctors' [online] http://bma.org.uk/practical-support-at-work/ewtd/ewtd-juniors (accessed 11 December 2014).

Casey, A.L., Burnell, S., Whinn, H., Worthington, T., Faroqui, M.H. and Elliott, T.S. (2007) 'A prospective clinical trial to evaluate the microbial barrier of a needleless connector', The Journal of Hospital Infection, Vol. 65, No. 3, pp.212-218.

Castro-Sanchez, E., Charani, E., Drumright, L.N., Sevdalis, N. and Holmes, A.H. (2014) 'Fragmentation of care threatens patient safety in peripheral vascular catheter management in acute care - a qualitative study', PLos ONE, Vol. 9, No. 1, p.e86167.

Curran, E. and Reilly, J. (2008) 'Optimising peripheral vascular catheter care offers the greatest potential for prevention of vascular-device-related infections', The Journal of Hospital Infection, Vol. 69, No. 3, p.307.

Department of Health Social Services and Public Safety (2000) Junior Doctors Contract [online] http://www.dhsspsni.gov.uk/jdcpayguide.pdf (accessed 11 December 2014).

Esteve, F., Pujol, M., Limson, E. et al. (2007) 'Bloodstream infection related to catheter connections: a prospective trial of two connection systems', The Journal of Hospital Infection, Vol. 67, No. 1, pp.30-34.

European Commission Directive 2010/32.EU, 'Implementing the Framework Agreement on prevention from sharp injuries in the hospital and healthcare sector concluded by HOSPEEM and EPSU, Official Journal of the European Union, COUNCIL DIRECTIVE 2010/32/EU of 10 May 2010: L134-66' [online] https://osha.europa.eu/en/legislation/directives/sectorspecific-and-worker-related-provisions/osh-directives/council-directive-2010-32-euprevention-from-sharp-injuries-in-the-hospital-and-healthcare-sector (accessed 11 December 2014).

General Election (2010) Frequently Asked Questions [online] http://www.kingsfund.org.uk/ projects/general-election-2010/faqs (accessed 11 December 2014).

Haeseler, G., Hildebrand, M. and Fritcher, J. (2014) 'Evaluation of a peripheral vein catheter with blood control septum', Journal of Vascular Access, Vol. 15, No. 3, pp.221-222.

Health and Safety at Work Act (1974) [online] http://www.legislation.gov.uk/ukpga/1974/37/pdfs/ ukpga_19740037_en.pdf (accessed 11 December 2014).

Health and Safety Executive (HSE) (2013) 'Health and safety (sharp instruments in healthcare) regulations, guidance for employers and employees' [online] http://www.hse.gov.uk/pubns/hsis7.pdf (accessed October 2015).

Institute for Innovation and Improvement (2014) Productive Series Putting Patients First [online] http://www.institute.nhs.uk/quality_and_value/productivity_series/the_productive_series.html (accessed 11 December 2014).

Jagger, J., Perry, J., Parker, G. and Kornblatt, P.E. (2011) 'Blood exposure risk during peripheral I.V. catheter insertion and removal', Nursing, Vol. 41, No. 12, pp.45-49.

Maki, D.G., Klugger, D.M. and Crinch, C.J. (2006) 'The risk of bloodstream infections in adults with different intravascular devices: a systematic review of 200 published prospective studies', Mayo Clinic Proceedings, Vol. 81, No. 9, pp.1159-1171.

NHS Business Service Authority (2014) NHS Business Service Authority Business Plan 2014-2015 [online] http://www.nhsbsa.nhs.uk/Documents/NHSBSAAnnualReports/NHSBSA_Business Plan_2014-15 (V1) 05.2014.pdf (accessed 11 December 2014). 
NHS Careers (2013) NHS Careers Agenda for Change Pay Rates [online]

$\mathrm{http}$ ://www.nhscareers.nhs.uk/working-in-the-nhs/pay-and-benefits/agenda-for-change-payrates/ (accessed 11 December 2014).

NHS Confederation, 'Key statistics on the NHS' [online] http://www.nhsconfed.org/resources/keystatistics-on-the-nhs (accessed 11 December 2014).

NHS Employers (2014) Pay and Conditions Circular (M\&D) 2/2014 Pay Award for Hospital Medical and Dental Staff, Doctors and Dentists in Public Health, the Community Health Service and Salaried Primary Dental Care [online] http://www.nhsemployers.org/ /media/ Employers/Publications/Pay\%20circulars/Pay-Circular-MD-2-2014.pdf (accessed 11 December 2014).

NHS England (2013) Better Procurement Better Value Better Care: A Procurement Development Programme for the NHS [online] https:/www.gov.uk/government/uploads/system/uploads/ attachment_data/file/226835/procurement_development_programme_for_NHS.pdf (accessed 11 December 2014).

NHS England (2014) The Mandate A Mandate from the Governments to NHS England April 2014 to March 2015 [online] https://www.gov.uk/government/uploads/system/uploads/attachment data/file/256406/Mandate1415.pdf (accessed 11 December 2014).

NHS Supply Chain [online] http://www.supplychain.nhs.uk/news/company/150m-cash-releasingsavings-to-be-delivered-by-march-2016/ (accessed 11 December 2014).

NHS Supply Chain Catalogues [online] http://www.supplychain.nhs.uk/ (accessed 11 December 2014).

Niel-Weise, B.S., Daha, T.J. and van der Broek, P.J. (2006) 'Is there evidence for recommending needleless closed catheter access systems in guidelines?', The Journal of Hospital Infection, Vol. 62, No. 4, pp.406-413.

O'Grady, N.P., Alexander, M., Burns, L.A. et al. (2011) 'Guidelines for the prevention of intravascular catheter-related infections', American Journal of Infection Control, Vol. 39, No. 4, Supplement 1, pp.S1-34.

Onia, R., Eshun-Wilson, I., Arce, C. et al. (2011) 'Evaluation of a new safety peripheral IV catheter designed to reduce mucocutaneous blood exposure', Current Medical Reearchs Opinion, Vol. 27, No. 7, pp.1339-1346.

Oxford Dictionary (2014) [online] http://www.oxforddictionaries.com/definition/english/falseeconomy (accessed 11 December 2014).

Payscale, 'Staff nurse salary on payscale' [online] http://www.payscale.com/research/UK/ Job=Staff_Nurse/Salary (accessed 11 December 2014).

Prunet, B., Meaudre, E., Montcriol, A., Asencio, Y., Bordes, J., Lacroix, G. and Kaiser, E. (2008) 'A prospective randomized trial of two safety peripheral intravenous catheters', Anesthesia and Analgesia, Vol. 107, No. 1, pp.155-158.

Seiberlich, L.E., Keay, V., Kallos, S. et al. (2015) 'Clinical performance of a new blood control peripheral intravenous catheter: a prospective, randomized, controlled study', International Emergency Nursing [online] http://dx.doi.org/10.1016/j.ienj.2015.08.005.

Sharpe, D. (2015) 'Your chi-squared test is statistically significant: now what?', Practical Assessment, Research and Evaluation, Vol. 20, No. 8, pp.1-10, ISSN: 1531-7714 [online] http://pareonline.net/getvn.asp? $\mathrm{v}=20 \& \mathrm{n}=8$ (accessed 23 November 2015).

Shillie, S., Murphy, T.V., Sawyer, M. et al. (2013) Centre for Disease Control and Prevention: Guidance for Evaluating Health-Care Personel for Hepatitis B Virus Protection and for Administering Postexposure Management [online] http://www.cdc.gov/mmwr/preview/ mmwrhtml/rr6210a1.htm (accessed 11 December 2014).

Soothill, J.S., Bravery, K., Ho, A., Macqueen, S., Collins, J. and Lock, P. (2009) 'A fall in bloodstream infections followed a change to $2 \%$ chlorhexidine in $70 \%$ isopropanol for catheter connection antisepsis: a pediatric single centre before/after study on haemopoietic stem cell transplant ward', American Journal of Infection Control, Vol. 37, No. 8, pp.626-630. 